\title{
DIAPHYSEAL FRACTURES OF ULNA AND RADIUS WITH SOFT TISSUE BREACH- OUR EXPERIENCE WITH SQUARE NAIL FIXATION
}

\author{
P. Anil Babu'1, V. V. Narayana Rao ${ }^{2}$
}

${ }^{1}$ Assistant Professor, Department of Orthopaedics, Guntur Medical College, Guntur, Andhra Pradesh. ${ }^{2}$ Associate Professor, Department of Orthopaedics, Guntur Medical College, Guntur, Andhra Pradesh. ABSTRACT

\section{BACKGROUND}

Fractures involving radius and ulna comprise a major part of commonly occurring fractures. They are commonly seen across all age groups. A nail which is having square like cut section can be held in a circular medullary canal with inherent stability offered by its design.

Our study is to know how far square nail fixation for forearm fractures can give optimal results in different fracture patterns in soft tissue breaches.

\section{MATERIALS AND METHODS}

Our study is done to know the efficacy of the square nails in fixation of the fractures in the forearm. We have included 86 cases of fractures of radius and ulna in 68 patients. All these cases have sustained fractures along with soft tissue injuries in the plane of the surgery, in the volar and dorsal aspects of the forearm.

\section{RESULTS}

The average time taken by the fractures to show soft callus is 7 weeks from which time assisted movements are initiated. The segmental and comminuted fractures took more than average time to show callus, which is seen on an average at 9 weeks.

\section{CONCLUSION}

The square nails are useful for fracture fixation in fractures of forearm. The square nail insertion requires no or less soft tissue dissection. The cases in our study are showing callus formation in average time for the given fracture and pattern avoiding overriding, rotational deformities.

\section{KEYWORDS}

Fractures of Forearm, Diaphyseal Fractures, Square Nail Fixation, Soft Tissue Breaches.

HOW TO CITE THIS ARTICLE: Babu PA, Rao VVN. Diaphyseal fractures of ulna and radius with soft tissue breach- our experience with square nail fixation. J. Evolution Med. Dent. Sci. 2017;6(40):3193-3196, DOI: 10.14260/Jemds/2017/690

\section{BACKGROUND}

Fractures involving radius and ulna comprise a major part of commonly occurring fractures. They are commonly seen across all age groups.(1) The mechanisms of these injuries is essential to plan for the management and to consider the possible outcomes to have better outcomes. The recent studies have made it a point that open reduction and internal fixation gives better outcomes in fractures of both bones of forearm. Although, open reduction and internal fixation is considered a standard treatment method in forearm diaphyseal fractures, it is not possible and advisable in all the cases.(2) Compromised soft tissue cover at times will force the decisions other than open reduction and internal fixation with plating. Conservative treatment of forearm fractures is often associated with complications of casting leading to loss of reduction in the casting, complication of compartment syndrome and malunion. Frequent inspection of the skin is required at times if the patients are presenting with simultaneously sustained injuries to skin.

Financial or Other, Competing Interest: None.

Submission 11-04-2017, Peer Review 04-05-2017,

Acceptance 11-05-2017, Published 18-05-2017.

Corresponding Author:

Dr. P. Anil Babu,

\#5-54-120, 101 Suryodaya Residency,

6/18, Brodipet, Guntur-522002,

Andhra Pradesh.

E-mail: anilpbabu@gmail.com

DOI: $10.14260 /$ jemds $/ 2017 / 690$
Especially, this is so in road traffic accidents resulting in technically compound fractures with abrasions, lacerations and contusions. The plane of dissection in case of fracture both bones in such road traffic accidents is not available without breaches to approach the bone for managing with gold standard techniques. Plate osteosynthesis is the most commonly used technique for the treatment of diaphyseal forearm fractures in adults. However, the application of a plate can lead to disrupted periosteal blood supply and the dissection may lead to large incisions, necessitates skin incisions, may be difficult to heal.(3) Fractures like both bone forearm, which come under influence of torsional forces are better treated by devices which can overcome these forces and still cause least soft tissue damage. Probably, this is one reason why these fractures frequently get displaced in POP castings.

Going by the fracture pattern, intramedullary fixation becomes the option to rely on in segmental fracture patterns, oblique fractures, comminuted fractures. Open reduction will be an option in fracture patterns where, fracture surface is longer, requires very big incisions, to apply plate on the intact surface. Long incisions in case of both bone fractures may not ideally have the gap between two incisions, which finally results in difficulty in closure of the surgical wound and subsequent swelling in the post-operative period.

Like any other fracture, diaphyseal fractures of radius and ulna present specific issues. The outcome is very much dependant on regaining length, apposition, axial alignment achieving normal rotational alignment. All these issues when 
properly addressed can have near total range of movements irrespective of the fixation device.

The major forces that can displace the fractures in forearm are generated by Biceps, Supinator proximally and Pronator quadratus distally. Specific positions for immobilising the fracture must be followed till such fractures are fixed to neutralise these forces. Proximal one-third fractures are immobilised in supination, middle one-third fractures are immobilised in mid prone position and distal one-third fractures in pronation.(4)

Closed fixation has many advantages, frequently a relatively short operating time with minimal surgical trauma, low incidence of infection, less blood loss, no periosteal stripping, better facilitated union, small scars and minimal compromise to bone vascularity.

A nail which is having square-like cut section can be held in a circular medullary canal with inherent stability offered by its design. This design has been advocated by AK Talwalkar with a series of cases.(5)

The nail is simple in design with varying tips for the usage in Ulna and Radius. It is made with a sharp pointing end for ulna and sloping edge at the tip for Radius.

Square nails are better suited in a situation for fractures in forearm, where open reduction is not planned for both soft tissue and fracture pattern related issues.

\section{MATERIALS AND METHODS}

It is an observational study. Our study is done to know the efficacy of the square nails in fixation of the fractures in the forearm. We have included 86 cases of fractures of radius and ulna in 68 patients. All these cases have sustained fractures along with soft tissue injuries in the plane of the surgery, in the volar and dorsal aspects of the forearm. The soft tissue injuries are ranging from contusion, abrasions to lacerations in the plane used for open reduction and internal fixation. The fracture patterns involved in our study are transverse, oblique, spiral, segmental and comminuted fractures. Our study is designed to include the different fracture patterns in forearm with soft tissue breaches and to observe the outcome in terms of union achieved at the fracture site, whether it is as per the average union time in the forearm for the given fracture pattern or not.

The patients are evaluated for their fitness to undergo surgery and to rule out co-existing life-threatening, limb threatening injuries.

\section{Inclusion Criterion}

Fractures of ulna and/or radius in the diaphyseal regions, all fracture patterns, adult mature bones, soft tissue breaches on the volar and dorsal aspects of forearm.

\section{Exclusion Criterion}

Type IIIB, C open fractures of Gustilo-Anderson, other fractures in the same limb, tendon injuries in the same limb, avulsion injuries.

\section{Pre-Operative Preparation}

The skin of the forearm with the fracture is thoroughly cleansed with lavage onto breached sites with normal saline and $5 \%$ Povidone Iodine and $\mathrm{H}_{2} \mathrm{O}_{2}$. The normal looking intact skin, contused skin are painted with $10 \%$ Povidone Iodine. The fractured limb is given a POP Slab upto above elbow, in supination for proximal on third, mid-prone for middle onethird, pronation for distal one-third fractures. The limbs are kept absolutely elevated and patients are advised to do active finger movements as tolerated.

\section{Surgical Technique}

After routine preparation and draping of the skin entry points are kept for introduction of the square nails. Entry point for ulna is kept with straight bone awl and a curved awl is used for radius. The size of the square nails is measured for their diameter as well as length on the table under image intensifier. The diameter of the square nail is decided by the width of the medullary canal at the narrowest part of the bone.

The entry point for ulna is kept at the tip of the olecranon in line with the medullary canal in AP and Lateral views. The entry point for radius is kept lateral to Lister's tubercle or at the lateral aspect of radial styloid.

The square nail of chosen diameter is inserted and pushed further with a mallet. Fractures which are reduced by traction and counter traction at this stage got closed reduction and nail is further introduced into the other fragment to be inserted into the cortical bone.

The reduction of the transverse fractures is comparatively easy. Fractures which could not be reduced by traction methods and fractures which are reduced with rotational deformity are reduced with a small incision to hold the fragments in alignment with the fragment, which has received an entry point. The dissection is limited not to involve the periosteum. This minimal dissection is carefully done, not to lose any fragments in comminution and segmental fractures wherein only one fragment is held to get the reduction.

All the cases are again given immobilisation like preoperative immobilisation and advised limb elevation and to continue active finger movements. Dressings of the breached areas are done once in two days. Suture removal at the entry points and minimal dissection sites are done at tenth postoperative day.

The patients are discharged with an advice to come for review at two weeks intervals till eighth post-operative week. The immobilisation is discontinued with POP slab from sixth week onwards and are advised assisted movements at wrist and elbow, while being supported by an arm sling.

The post-operative radiographs are taken at fourth, sixth and eighth week intervals.

The fractures are then monitored with fracture union whether it is progressing at average time or not for the given fracture pattern. Chi squared statistic and $P$ value are used to analyse the results in diaphyseal fractures of both bones of forearm fractures for the time taken by them to unite by fixation with square nails.

\section{RESULTS}

Out of 86 fractures in 50 patients had single bone fracture and 18 have both bones fracture in our study, all the cases are treated with square nails with entry point wounds measuring $1 \mathrm{~cm}$. The fractures of ulna alone are 38, radius alone are 12 and both bones forearm are 18 .

The fracture patterns treated were transverse, oblique, segmental and comminuted. There are 14 transverse fractures, 38 oblique fractures, 15 segmental fractures and 19 comminuted fractures. 
Fractures reduced with traction are 34 and with minimal dissection are 52 .

The fractured limbs have shown decreased oedema due to initial trauma from third post-operative day. There were 8 superficial infections noted in the limbs presenting with deep lacerations, which finally healed with local measures.

The fractures are monitored with serial radiographs in the post-operative period. The average time taken by the fractures to show soft callus is 7 weeks, from which time assisted movements are initiated.

The Results are Analysed as given below

The fracture pattern, time taken for union and nail migration are given in Table 1.

\begin{tabular}{|c|c|c|c|c|c|c|}
\hline Pattern & Cases & $\begin{array}{l}\text { Time taken for } \\
\text { Soft Callus }\end{array}$ & $\begin{array}{c}\text { Migration } \\
\text { of Nail }\end{array}$ & $\begin{array}{c}\text { Delay in } \\
\text { Union }\end{array}$ & $\begin{array}{c}\text { Union at } \\
\text { Average Time }\end{array}$ & Total \\
\hline Transverse & 14 & $6-8$ & 2 & 2 & 12 & 14 \\
\hline Oblique & 38 & $6-8$ & 1 & 1 & 37 & 38 \\
\hline Segmental & 15 & $8-10$ & 2 & 2 & 13 & 15 \\
\hline Comminuted & 19 & $8-10$ & 3 & 3 & 16 & 19 \\
\hline
\end{tabular}

The results are analysed for the time taken by each fracture pattern when treated with square nail, whether it is at an average time for the given fracture or more than that in Table 2 as given below.

\begin{tabular}{|c|c|c|c|c|c|c|}
\hline Pattern & Cases & $\begin{array}{c}\text { Time taken } \\
\text { for Soft Callus }\end{array}$ & $\begin{array}{c}\text { Migration } \\
\text { of Nail }\end{array}$ & $\begin{array}{c}\text { Delay in } \\
\text { Union }\end{array}$ & $\begin{array}{c}\text { Union at } \\
\text { Average Time }\end{array}$ & Total \\
\hline Transverse & 14 & $6-8$ & 2 & 2 & 12 & 14 \\
\hline Oblique & 38 & $6-8$ & 1 & 1 & 37 & 38 \\
\hline Segmental & 15 & $8-10$ & 2 & 2 & 13 & 15 \\
\hline Comminuted & 19 & $8-10 \quad 3$ & 3 & 16 & 19 \\
\hline \multicolumn{7}{|c|}{ Table 2 } \\
\hline
\end{tabular}

The chi-square statistic is 3.6529 . The $\mathrm{p}$-value is .301466 . The result is not significant at $\mathrm{p}<.05$
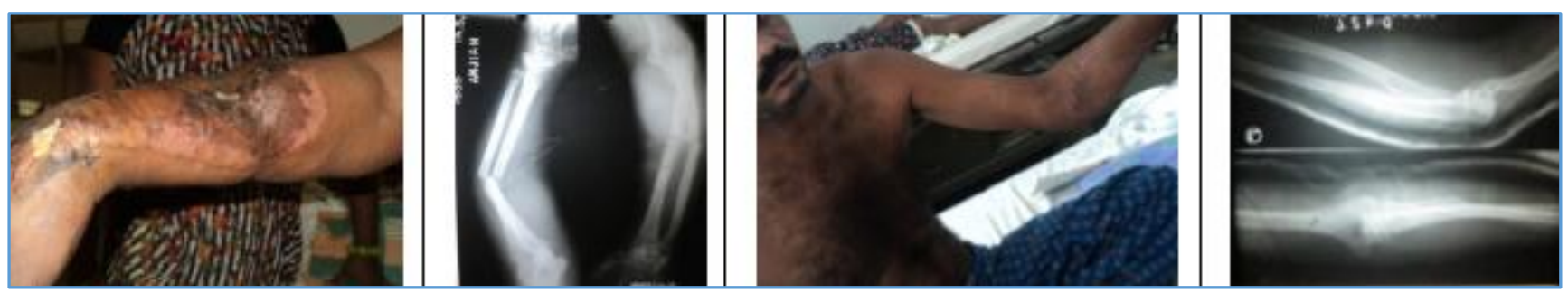

Figures 1. Fractures with Soft Tissue Breaches
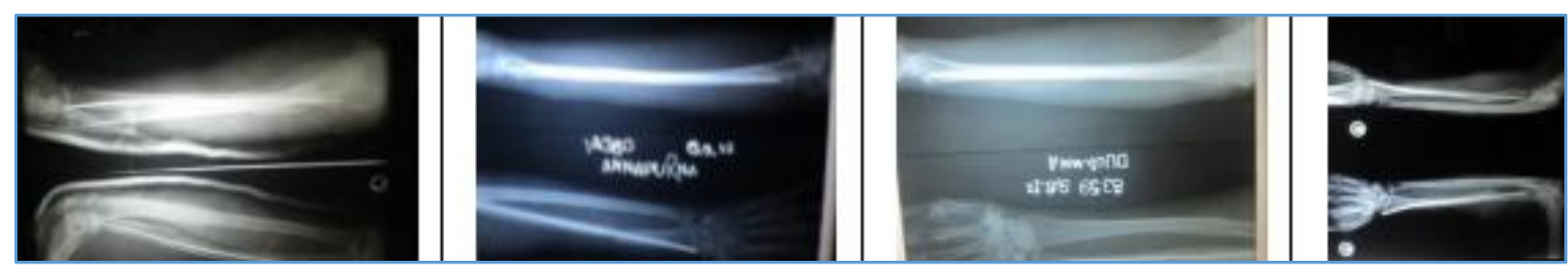

Figures 2. Post-Operative Radiographs

\section{DISCUSSION}

The square nails are useful for fracture fixation in fractures of forearm. The square nail insertion requires no or less soft tissue dissection. Fractures of both bones of the forearm where they are fractured due the angulatory and rotational strains present difficulty not only in reduction but also in its maintenance. Therefore, these injuries, particularly in adults where the compensatory mechanisms of childhood are lacking, are difficult to treat. Fracture reduction which is achieved with traction and counter traction can be maintained with square nail fixation, which offer stability due to their inherent design. Talwalkar on the assumption that a square nail inserted in a round medullary cavity would provide sound fixation. Square nail design offers consistent intramedullary hold on the fragments.(6) 
The usage of intramedullary nails is also tried previously. In the early 1980s surgeons in Nancy, France, developed an elastic stable intramedullary nail based on a theoretical concept by Firica. Previous experience had suggested that elasticity and stability were not easily combined in one construct. However, working from the concept of three-point fixation used with a single Rush nail, these surgeons were able to improve stability significantly by using two pretensioned nails inserted from opposite sides of the bone. Metazieau, Ligier and their colleagues were able to show that titanium nails which were accurately contoured and properly inserted could impart excellent axial and lateral stability to diaphyseal fractures in long bones. Rotational stability was also better than had previously been experienced.(7)

The square nails may not get contoured when they are negotiated through natural curvature. Their effect of giving a rigid fixation is and its consequences are described by Dave et al. The point made against nailing has been the loss of radial bow and its impact on function. Radius and ulna have a complex anatomic relationship and their relative lengths and curves are necessary for full range of supination and pronation movements. The elbow and wrist joints also do not allow much compensation for the loss of these movements, but shoulder joint enjoys considerable freedom and may compensate for the loss functionally. ${ }^{(8)}$

The cases in our study are showing callus formation in average time for the given fracture and pattern avoiding overriding, rotational deformities. The soft tissue breaches occurred along with the fracture are showing good healing with a stable fracture with square nail fixation.

The fixation with square nails for fractures of forearm is to be considered as an alternative to plating. The minimal soft tissue dissection also avoids contractures and big scars and issues with wound healing.

\section{CONCLUSION}

The square nails are useful for fracture fixation in fractures of forearm. The square nail insertion requires no or less soft tissue dissection. The cases in our study are showing callus formation in average time for the given fracture and pattern avoiding overriding, rotational deformities. The soft tissue breaches occurred along with the fracture are showing good healing with a stable fracture with square nail fixation.

\section{REFERENCES}

[1] Al-Sadek TA, Niklev D, Al-Sadek A. Diaphyseal fractures of the forearm in adults, plating or intramedullary nailing is a better option for the treatment? Open Access Maced J Med Sci 2016;4(4):670-3.

[2] Visna P, Vlcek M, Valcha $M$, et al. Management of diaphyseal forearm fractures using LCP angle-stable fixation devices and intramedullary nailing. Rozhl Chir 2009;88(12):708-15.

[3] Lil NA, Makkar DS, Aleem AA. Results of closed intramedullary nailing using Talwarkar square nail in adult forearm fractures. Malays Orthop J 2012;6(3):7-12. nadeemlil@yahoo.com

[4] Bansal H. Intramedullary fixation of forearm fractures with new locked nail. Indian J Orthop 2011;45(5):410-6. hbansal@drhbf.org

[5] Ghosh S, Chowdhury A, Chaudhuri A, et al. Rush nail and management of fracture both bone forearm. J Sci Soc 2014;41(3):167-72.

[6] Talwalkar AK. Treatment of simple fractures of radius and ulna with internal fixation and without external support. IJO 1967;1(1):2630.

[7] Barry M, Paterson JMH. Aspects of current management. Flexible intramedullary nails for fractures in children. The J Bone \& Joint Surg 2004;86-B:947-53.

[8] Dave MB, Parmar KD, Sachde BA, et al. The radial bow following square nailing in radius and ulna shaft fractures in adults and its relation to disability and function. Malaysian Orthopaedic Journal 2016;10(2):1115. 